\title{
Research on Power Grid Enterprise Financial Information Construction Based on Cloud Computing
}

\author{
Wenrui GAO \\ Finance and Assets Department \\ State Grid Shaanxi Electric Power Company \\ Xi' an Shaanxi, China \\ E-mail: duanlaiyue@126.com
}

\author{
Peng ZHANG \\ Finance and Assets Department \\ State Grid Shaanxi Electric Power Company \\ Xi'an Shaanxi, China \\ E-mail: duanlaiyue@126.com
}

\begin{abstract}
The article put forward concrete construction programs for power grid enterprises encountered in the financial management by analyzing the feasibility of fusing integration cloud computing and power grid enterprises financial management. The scheme is about requirements analysis and a series of specific construction method for deploying embodiment in the context of cloud computing to meet its flexibility, personalization, diversity needs.
\end{abstract}

Keywords-cloud computing; power grid enterprises; finance management; information construction

\section{INTRODUCTION}

Cloud computing its advanced technology and concepts to subvert the traditional model of computing, network architecture and business model, we are undergoing a technological and industrial change. While the application of cloud computing is still in its infancy, and faces a number of challenges, but with the advances in technology, establishing sound laws and regulations, governments and businesses continue to pay attention to the benefits of cloud computing will be more and more recognized by people.

\section{LITERATURE REVIEW}

Since August 9, 2006, Google formally proposed "cloud computing" concept, the international all Internet companies gradually began research on cloud computing. With the rapid development of the global cloud computing market, the world information industry of countries and regions have put the cloud computing as the focus of future development, they want to seize the first cloud computing industry highest point [1]. In the IT business, Google, Microsoft, Amazon, IBM, Sun and other companies are growing cloud computing business, Intel, Cisco and other traditional hardware vendors are toward cloud computing [2], and because of the pursuit of international capital markets cloud computing is growing very fast. Lu Cheng etc. demonstrates the importance of measures to cloud computing for SMEs and gives a choice of cloud services and methods to cope with risks $[3,4]$. Xu Weiping etc. think SMEs financial information construction by cloud computing is a convenient and efficient means[5]. $\mathrm{He}$ Ying explore the feasibility of large-scale enterprise applications cloud computing information construction [6].

Cloud computing will finance information construction easier to use, resource conservation and environmental protection, to achieve information sharing and real-time synchronization, effectively reduce information technology costs, and simplify the process of information. Cloud-based financial information for building model will be able to comprehensively improve the level of financial information. Cloud computing in the financial aspects of the application is still in the growth stage, most of the literature are only staying at several levels of cloud computing technology, theory, influence, etc., the lack of mature application cases for reference.

\section{Cloud COMPuting AND POWER ENTERPRISE FINANCIAL MANAGEMENT INFORMATION}

\section{A. Demand grid Enterprise Financial Management}

In today's society, with the increasing competitiveness of enterprises, enterprises should continue to expand their business and expand their scale, but traditional financial management software has been far from satisfying the needs of enterprises. Grid In the traditional mode, grid enterprises building a financial information by the software vendor for enterprise development financial management software, It requires grid enterprises to invest a lot of manpower and financial resources for the procurement of hardware, software licensing, management, maintenance and other inputs, but because of China's power grid business operations of large-scale, this is just only meet part of the demand grid enterprises.

With the acceleration of the reform of the power enterprises, in the current competition in the market, power enterprises in order to occupy a favorable position, you must use information technology tools, play to their advantages of production and management, improve the market competitiveness and ability to withstand risks. Cloud computing has brought a hope to the current grid business financial management information construction. Grid enterprises can use cloud computing to speed up its pace of information technology, and improving economic efficiency, achieve financial management system consists of information to "cloud computing" technology.

\section{B. Power Grid Enterprise Financial Management Principle Of Cloud Computing}

Power grid enterprises can take advantage of cloud computing high degree of flexibility, scalability, compatibility, by establishing standard operating environment template control mechanism, unified enterprise 
accounting system, work practices, business processes, rapid to realize the integration and control information. Ensure the overall standardization of financial accounting, strengthen internal management functions, enhancing the overall level of enterprise financial management, to achieve efficient coordination between the headquarters and relevant companies, between internal and external.

By "financial cloud" model, software applications and data stored in the cloud, enabling centralized management of information resources, shared interaction and optimize the allocation, breaking the "information island" phenomenon between the business sector and related enterprises. In cloud computing, data can achieve a higher level of integration, handling, mining, real-time updates and sharing, enhance the added value, and enterprises more conducive to the establishment of a unified financial information platform.

Centralized financial management through the financial information platform, the original distributed base business from branches, subsidiaries pulled out to concentrate financial data center. Through standardization, harmonization and standardization of accounting, reducing basic business approval, processing level and time, to ensure financial information timeliness and accuracy, control financial risks and improve work efficiency. In addition, the accountants of affiliated business unit detached from a lot of tedious business base out, have more energy and time to devote to financial management and decision-support work.

IV. Cloud-BAsed COMPuting Power GRID ENTERPRISE FINANCIAL MANAGEMENT INFORMATION BUILDING SOLUTIONS

\begin{tabular}{|c|c|c|}
\hline $\begin{array}{c}\text { Non-functional } \\
\text { requirements }\end{array}$ & $\begin{array}{c}\text { Demand analysis } \\
\text { Core functional } \\
\text { requirements }\end{array} \quad \begin{array}{c}\text { Expand functional } \\
\text { requirements }\end{array}$ \\
\hline
\end{tabular}

\begin{tabular}{|c|c|c|}
\hline \multicolumn{3}{|c|}{ Planning and design } \\
\hline \multicolumn{2}{|c|}{$\begin{array}{c}\text { Optimization of } \\
\text { organizational structure }\end{array}$} & $\begin{array}{c}\text { Financial Business } \\
\text { Process Reengineering }\end{array}$ \\
\hline Staffing & Service level & Cloud Service Sele \\
\hline
\end{tabular}

\begin{tabular}{|c|}
\hline \multicolumn{2}{|c|}{ Deployment of the implementation } \\
\hline Self-built "private financial cloud" \\
\hline
\end{tabular}

\begin{tabular}{|c|c|}
\hline $\begin{array}{c}\text { Orivate financial cloud for the } \\
\text { operation Management }\end{array}$ & $\begin{array}{c}\text { Public financial cloud for the } \\
\text { operation Management }\end{array}$ \\
\hline
\end{tabular}

Improved optimization

Figure 1. "Financial cloud" building basic flow

Financial Cloud building is a huge one project, running and long-term development of the business relations, it must be long-term vision and planning system. Financial Cloud building generally need to five steps, specifically demand analysis, planning and design, deployment implementation, operation and maintenance management and optimization improvements, as shown in Fig. 1.

\section{A. Demand Analysis}

Enterprises decided to implement build "financial cloud", and the important prerequisite is to do all the needs of research and analysis. "Financial cloud" mode enables centralized financial management, through standardization, harmonization and standardization of accounting, not only to ensure the timeliness of financial information, accuracy, and improve work efficiency. By "financial cloud" model, software applications and data stored in the cloud, enabling centralized management of information resources, shared interaction and optimize the allocation, breaking the "information island" phenomenon between the business sector and related enterprises, and enterprises through the establishment of a unified financial information platform, to meet the different accounting system as the premise, the unified accounting, and accounting policies and other codes etc.. It helps ensure standardization of financial accounting overall business, and strengthen internal management functions, enhance the overall level of corporate financial management. For the construction and use of financial information system, divided into the following areas:

\section{1) Non-functional requirements}

It is outside the functional requirements, and system construction and application of the relevant factors, including: security, ease of use, scalability, flexibility, reliability, dynamic and so on.

\section{2) Core functional requirements}

It is to deal with the company's financial management business, integrated in the "financial cloud" system function modules, including: base system, general ledger, fixed asset management, compensation management system, report management system etc.

\section{3) Expand functional requirements}

Based on the "financial cloud", in line with the company's operations to build the expansion of functions, including customer management, supply chain management, human resources management, office automation, web portals, etc.

\section{B. Planning and Design}

Planning and design refers to "financial cloud" construction project to build a whole, including the following.

\section{1) Optimization of organizational structure}

"Financial cloud" applications some easily standardized and streamlined business taken out to construct a stand-alone operation of the "financial cloud data centers." Data center to customer demand as the guide, to provide customers with specialized services.

\section{2) Financial business process reengineering}

By collecting, carding, decomposition of existing business processes, to easily standardized and processoriented business transformation and restructuring, to improve business efficiency. 


\section{3) Staffing}

"Private financial cloud" model may have some financial officers re-assigned posts, while hire or train more highquality professional IT technical staff. "Public financial cloud" model to manage IT resources maintenance functions outsourced to cloud service providers.

\section{4) Service Level agreement}

SLA(Service Level Agreement) means the cloud service provider and the user reach a consensus in the service level and both aspects of responsibility to develop an agreement or contract by formal or informal consultations. Service Level Agreement clearly stated both cloud service provider and user responsibilities, rights and interests.

\section{5) Cloud service selection}

Cloud computing ecological industry chain comprises four core roles: owner, builders, operators and users. Owner mainly refers to the "private financial cloud" or "public finance cloud". User refers to "private financial cloud" or "public financial cloud" companies, departments and personnel. Builders refer to building cloud environments manufacturers, which is the variety cloud computing basic resources, technical solutions and service's provider. Operators refer to the vendors who are responsible for cloud computing environmental and service post-operation, maintenance, management.

\section{Deployment of the implementation}

1) Self - built "private financial cloud" in the process of implementing

Enterprises built "private financial cloud" can be taken to self-construction or technical service providers, it can be divided into three stages:

a) Construction of the resource pool. A resource pool is a carrier of cloud services, its construction needs three steps: (1)physical integration. Centralize IT resources through merger, consolidation and strengthen other means. (2)Logical consolidation. Divide software and hardware resources into different groups, making the application load evenly distributed to the group by the access layer to provide a unified interface in order to achieve scalability and high availability. (3)Virtualization, Map storage, networks, servers and other physical virtual to virtual resources by using virtualization technology to achieve IT resources flexible scheduling, dynamically allocated, share across domains and improve IT resource utilization.

b) Resource management platform. Resource management platform will centralized allocate management various resources in the resource pool, and prevent a single point of failure and viruses, data loss and other conditions of centralized management resources through safety management, quality management, service monitoring and data protection features.

c) Self-service construction. On the basis of preconstruction, construct a service-oriented private cloud: infrastructure clouds, platform cloud, application cloud. (1) Infrastructure cloud is used of the network to provide basic computing capacity, storage space and standardized services. (2)Cloud platform can provide users a cloud hosting platform which can develop application, test and run. (3)Application cloud construction can make users get a cloud application service provides by PC, tablet PCs, mobile phones and other devices.

2) Rent "public financial cloud" in the process of implementing

"Public cloud financial" is a service agreement to demand rent way to get the hardware and software resources via the Internet between the corporate users and the cloud service providers. Process is as follows:

a) Determining the intention of renting. According to preliminary demand analysis, combined with their own information needs characteristics, initially selected of a number of suitable product solutions.

b) Customization and orientation training. Cloud service providers according to the characteristics of their business create personalized initial program, and through on-site or online video ways for the use of personnel within the enterprise training.

c) The user free trial. Through the trial, business users can deeply feel the "cloud financial" application results to avoid blind investment.

d) Signed a service level agreement. Cloud service providers to provide services in accordance with the agreement, users pay fees in accordance with the standard rates and amounts.

e) Combined with the actual depth of customization. After the trial, enterprises combine with their own actual situation raised demand extensions and customization aspects to cloud service providers, cloud service providers customize on the basis of existing standards and services on the depth.

f) Delivered. After the trial, enterprises combine with their own actual situation raised demand extensions and customization aspects to cloud service providers, so that users can successfully complete the data migration and run.

\section{Operation and Maintenance Management}

The ultimate goal of financial information construction to support financial management. After the delivery of the construction, in order to ensure its reliability, availability, economy, security do a good job "financial cloud" in the daily operation and maintenance work is particularly important.

1) "Private financial cloud" for the operation and maintenance management

"Private financial cloud" is a financial application and data sharing service center, Cloud computing application is upgraded after the traditional financial data center. In order to manage the financial data centers, and establish a reliable, high-quality technical maintenance team which welldesigned organizational structure and personnel division, and fully mobilize the enthusiasm of staff to lay the foundation 
for "private cloud financial" of the operation and maintenance management.

2) "Public financial cloud" for the operation and maintenance management

As the "public cloud financial" operation and maintenance management is responsible by the cloud service provider, corporate users mainly involved in is to use it. In order to ensure service availability and reliability, it must be establish an effective "feedback - response" mechanism with the cloud service providers, there are self-service, remote online services and on-site service.

\section{E. Improved Optimization}

Financial information construction is a process of in the course of continuous testing, improvement and the cycle repeated. "Financial cloud" Optimization of improvement involves a wide range, Including the amount of hardware and layout is reasonable, software interface is easy to use, whether the application and business processes fit, the quality of service is excellent, whether scientific rules and norms, correct the problem that is in effect, etc.

\section{CONCLUSION}

Established cloud-based financial management information can solve power grid enterprise problem in fund, personnel and costs quickly and meet its flexibility, personalization and diversity needs, this will be the main trend of large enterprise financial information construction.

\section{REFERENCES}

[1] Pan Shige. Analysis of the impact of cloud computing on the accounting[J]. Periodical agency of yangtze university, 2010, 06:6667.

[2] Qin Rongsheng. The development of cloud computing and the challenges of accounting and auditing $[\mathrm{J}]$, Contemporary Finance \& Economics, 2013, 01:111-117.

[3] Lv Cheng, Yi Yanhong. Cloud accounting information construction SWOT analysis[J]. commercial accounting, 2013, 15:24-25.

[4] Wang Xin. Cloud environment for SMEs Financial Accounting Characteristics and Development Strategy[J], China Business \& Trade, 2013, 15:24-25.

[5] Xu Yuxia. Research on Construction of cloud-based enterprises accounting information. Securities \& futures of China, 2013, 09:147148.

[6] He Ying. Path and direction of enterprise group financial process reengineering based on cloud computing[j]. Management World, 2013,04:182-183. 